\title{
Biodegradation behaviors and water adsorption of poly(vinyl alcohol)/starch/carboxymethyl cellulose/clay nanocomposites
}

\author{
Mohammad Taghi Taghizadeh* and Narges Sabouri
}

\begin{abstract}
The focus of this work is to study the effect of sodium montmorillonite (MMT-Na) clay content on the rate and extent of enzymatic hydrolysis polyvinyl alcohol (PVA)/starch (S)/carboxymethyl cellulose (CMC) blends using enzyme cellulase. The rate of glucose production from each nanocomposite substrates was most rapid for the substrate without MMT-Na and decreased with the addition of MMT-Na for PVA/S/CMC blend $(51.5 \mu \mathrm{g} / \mathrm{ml} \mathrm{h}), \mathrm{PVA} /$ $\mathrm{S} / \mathrm{CMC} / 1 \%$ MMT $(45.4 \mu \mathrm{g} / \mathrm{ml}$ h), PVA/S/CMC/3\% MMT $(42.8 \mu \mathrm{g} / \mathrm{ml}$ h), and PVA/S/CMC/5\% MMT $(39.2 \mu \mathrm{g} / \mathrm{ml} \mathrm{h})$. The results of this study have revealed that films with MMT-Na content at $5 \mathrm{wt} . \%$ exhibited a significantly reduced rate and extent of hydrolysis. Enzymatic degradation behavior of MMT-Na containing nanocomposites of PVA/S/CMC was based on the determinations of weight loss and the reducing sugars. The degraded residues have been characterized by various analytical techniques, such as Fourier transform infrared spectroscopy, scanning electronic microscopy, and UV-vis spectroscopy.
\end{abstract}

Keywords: Nanocomposites; Carboxymethyl cellulose; Scanning electron microscopy; Cellulase

\section{Background}

Recently, non-degradable plastics have brought about a lot of concerns due to their polluting effects on the environment. In addition, the petroleum shortage is a real threat throughout the world. Considering these two problems, all countries are trying to develop environmentally friendly materials achieved from non-petroleum resources. Cellulose, as one of the most abundant polymers, is renewable and natural; furthermore, it has plenty of advantages such as reasonable cost, biodegradability, availability, considerable stiffness, thermal recyclability by combustion, and desired mechanical features. Besides, the low density of cellulose results in particular mechanical properties [1]. Therefore, instead of routinely used glass fiber or synthetic fiber as reinforcing elements in composite materials, cellulose can be successfully used due to its great advantages. In this regard, a large number of researches have been done on composites derived from petroleum-based polymers such as polyethylene and polypropylene reinforced with cellulose [2-4]. Regarding

\footnotetext{
* Correspondence: mttaghizadeh@tabrizu.ac.ir

Department of Physical chemistry, Faculty of Chemistry, University of Tabriz,
} P.O. Box 51666-16471, Tabriz, Iran incompatibility between polar and hydrophilic fibers and non-polar and hydrophobic matrix, a big problem will be brought about if cellulose fibers combine with thermoplastic matrix. For improving matrix reinforcement adhesion in composites, the surface of cellulose can be modified, either physically or chemically. The modification can be carried out by acetylation and alkali treatment [5]. Parallel with increase of awareness on environment, recently, more environmentally friendly and biodegradable materials have called a lot of attention. For fully biodegradable composites, considerable researches have been done on synthetic polymers having backbones like polylactic acid [6], polyvinyl alcohol (PVA) [7,8], and polycaprolactone [9] as potential matrix. Among synthetic water-soluble polymers throughout the world, PVA is the largest which has broad applications [10]. Interestingly, it possesses a lot of magnificent features such as high tensile strength, biodegradability, biocompatibility, chemical resistance, gas barrier, and excellent adhesive properties [11]. By preparing composites with more biodegradable and easily processable fillers such as cellulose, the cost and biodegradability of PVA can be decreased and enhanced, respectively. Due to 
the polar nature of both PVA and composites with natural polymeric materials, PVA is well suited for those composites. A lot of bio-degradable composites based on PVA have been prepared by incorporating natural polymeric materials such as pea starch [12], cellulose fibrils [13], wheat glen [14], etc. Carboxymethyl cellulose is a cellulose ether which shows thermal gelation and forms perfect films. In biocomposite film production, carboxymethyl cellulose can be used as filler due to its polymeric structure and high molecular weight. It is also capable of improving mechanical and barrier features of films based on starch [15]. Furthermore, the addition of fillers can improve the mechanical properties of this polymer. These composites could be used in packaging where good barrier and thermal properties are required [16]. One of the most advanced steps of polymer technology is developing polymer/clay nanocomposites. Interestingly, some of the properties of biodegradable polymers can be improved by preparing blends or nanocomposites using inorganic or natural fibers. Regarding thermoplastic starch-polyvinyl alcohol (TPS-PVOH) blends and their excellent compatibility and improved features such as tensile strength, elongation, toughness, and processability, predominantly further investigations on them are of particular interest. Compared to pure TPS, TPS-PVOH shows an improvement in melt strength [16]. Besides, to further improve the features of materials, plasticizers such as sorbitol, glycerol, and maltitol can be added to starch formulations $[17,18]$. In comparison to traditional composites, nanocomposites that resulted from adding a low amount of clay to polymers led to improvement in the properties such as barrier, thermal, and oxidative. Clay minerals are aluminum silicates categorized as phyllosilicates which are of a layered type. Since Montmorillonite is abundant and environmentally friendly with relatively low cost, it is one of the most commonly used layered silicates. The sodium montmorillonite (MMT$\mathrm{Na})$ clay possesses high surface area and is hydrophilic $[19,20]$. In 1975, Griffin increased the biodegradability by the aid of blending [21]. Bastioli et al. reported that the biodegradation of an amylose-PVA composite (PVA-starch blend) was very slow and that in a degradation test with activated sludge, $75 \%$ weight loss required 300 days. These two polymers can be an excellent pair for blending duo to their biodegradable features. In addition, PVA can mix evenly with the starch because of its water solubility [22]. Because of these facts, researches have focused a lot on PVA/starch. Starch/PVA/MMT and its blends have been tested in terms of enzymatic degradation [23,24]. Abbasi et al. reported enzymatic degradation tests on thermoplastic cellulose-clay nanocomposites [25]. At moderate temperatures and $\mathrm{pH}$ conditions, efficient enzymatic hydrolysis of cellulose could give glucose as follows [26]:

$$
\left(\mathbf{C}_{6} \mathbf{H}_{10} \mathbf{O}_{5}\right)_{n}+\mathbf{H}_{2} \mathbf{O} \stackrel{\text { Cellulase }}{\rightarrow} n \mathbf{C}_{6} \mathbf{H}_{12} \mathbf{O}_{6} .
$$

However, the enzymatic degradation of PVA/starch (S)/ xcarboxymethyl cellulose (CMC) nanocomposites and sodium montmorillonite clay has never been studied.

The current paper studies the cellulase action on PVA/ S/CMC composite film containing sodium montmorillonite nanoparticle at temperature $37^{\circ} \mathrm{C} \pm 1^{\circ} \mathrm{C}$. The modifications induced by the enzymatic treatment were evidenced by determination of weight loss, water absorption capacity, sugars released during biodegradation, as well as by UV spectroscopy, and total sugars were estimated by dinitrosalicylic acid (DNS) method [27].

\section{Methods}

\section{Materials}

Starch (S) was provided by Merck Company (Whitehouse Station, NJ, USA), and PVA $\left(M_{\mathrm{n}}=72,000\right)$ and glycerol

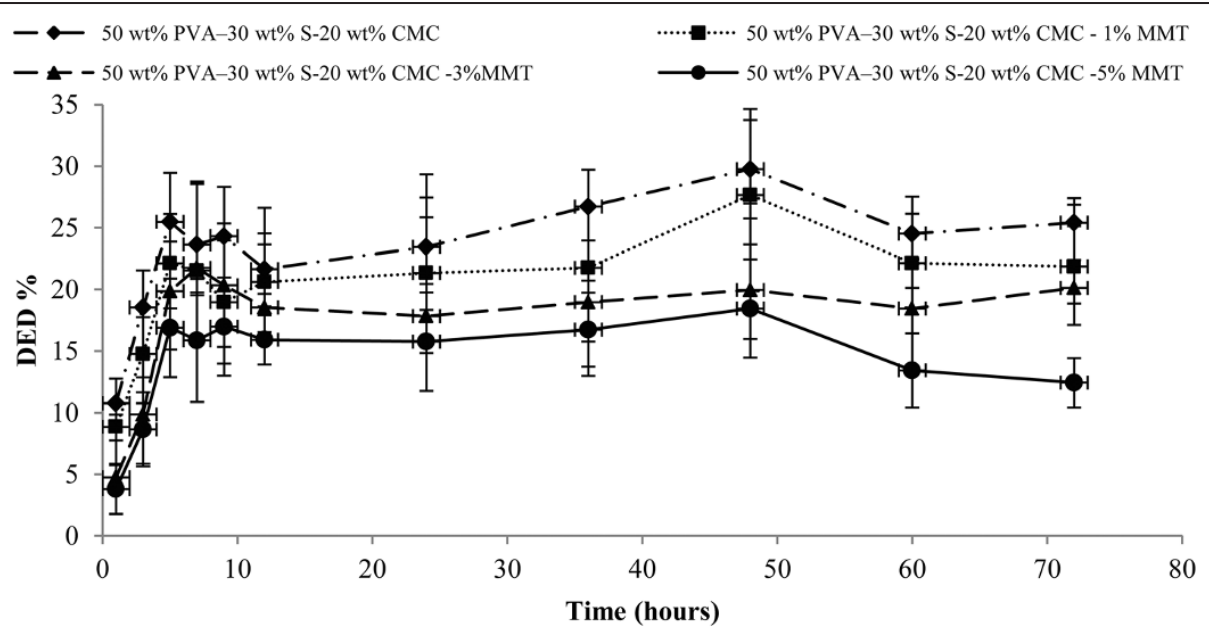

Figure 1 DED of nanocomposite films. Values are mean \pm standard deviation $(n=3)$. 


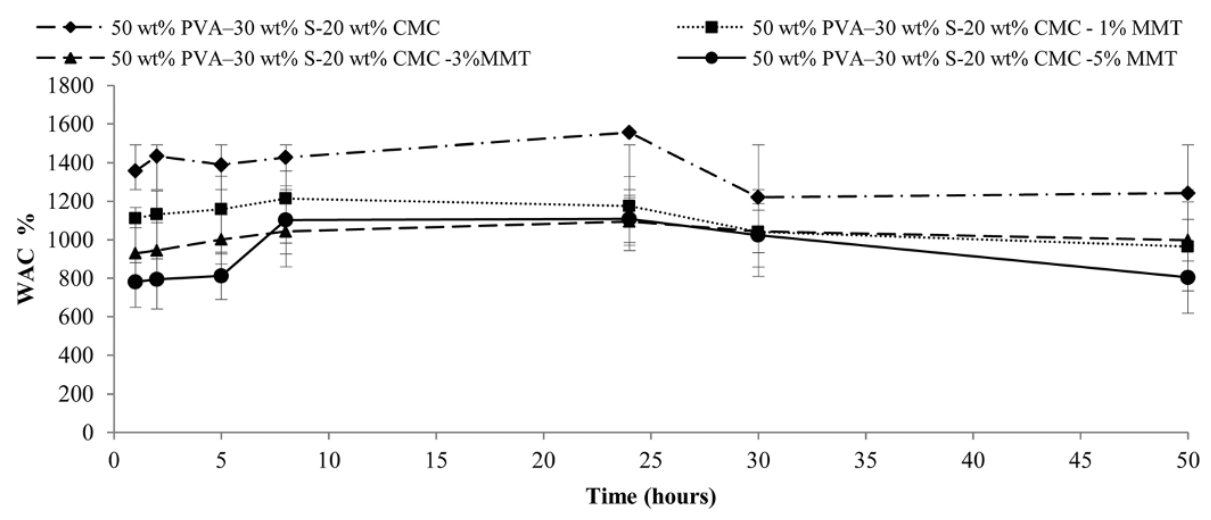

Figure $\mathbf{2}$ WAC of nanocomposite films. Values are mean \pm standard deviation $(n=3)$.

$\left(M_{\mathrm{n}}=92 / 10,78 \%\right.$ purity) were purchased from the same company. Carboxymethyl cellulose sodium salt, with an average molecular weight of $M_{\mathrm{n}}=295,225$ was purchased from Fluka Company (Buchs, Switzerland). Sodium montmorillonite $\left(\mathrm{Cloisite} \mathrm{Na}^{+}\right.$) with a cation exchange capacity of $92.6 \mathrm{meq} / 100 \mathrm{~g}$ clay was supplied by Nanocor Inc. (Arlington Heights, IL, USA). Reagent DNS was used for the determination of sugars released during degradation. Cellulase from Aspergillus niger (specific activity $111 \mathrm{U} \mathrm{mg}^{-1}$ ) and hydroxide sodium were provided by Fluka Company.

\section{Experiment}

The present work analyzes the enzymatic degradation behavior of some montmorillonite-containing nanocomposites of PVA/starch with CMC based on the determinations of weight loss and the reducing sugars. The nanocomposites have been prepared from $50 \mathrm{wt} . \%$ PVA-30 wt.\% S-20 wt.\% CMC containing small amounts of plasticizers, stabilizers, and destructuring agents (stabi-lizers or destructuring agents such as sodium montmorillonite clay and plasticizer such as glycerol) $[28,29]$. Biodegradation studies were carried out at $37^{\circ} \mathrm{C} \pm 1^{\circ} \mathrm{C}, \mathrm{pH}=4.8$, using cellulase for $72 \mathrm{~h}$.

\section{Enzymatic degradation test}

The enzymatic reaction mixture, comprising $1 \mathrm{ml}$ of cellulase and $25 \mathrm{ml}$ of $0.1 \mathrm{M}$ acetate buffer, was placed in clean conical flasks. The dried samples were cut into $4 \times 4 \mathrm{~cm}^{2}$ specimens, weighed, and immersed in the conical flasks. The flasks were placed in a shaking incubator with a rate of $70 \mathrm{rpm}$ for $72 \mathrm{~h}$ at $37^{\circ} \mathrm{C} \pm 1^{\circ} \mathrm{C}$. After $1,2,3,5,7,9,12$, $18,24,30,36,40,48,56,60$, and $72 \mathrm{~h}$, the samples were removed, rinsed with distilled water to remove the enzyme, dried, and weighed, respectively.

The degree of enzymatic degradation (DED) was calculated by the following equation:

$$
\mathrm{DED} \%=\left[\left(\mathrm{W}_{0}-\mathrm{W}_{\mathrm{d}}\right) / \mathrm{W}_{\mathrm{d}}\right] \times 100
$$

where $\mathrm{W}_{0}$ and $\mathrm{W}_{\mathrm{d}}$ represents the initial and final weights (before and after degradation, respectively) of the blends.
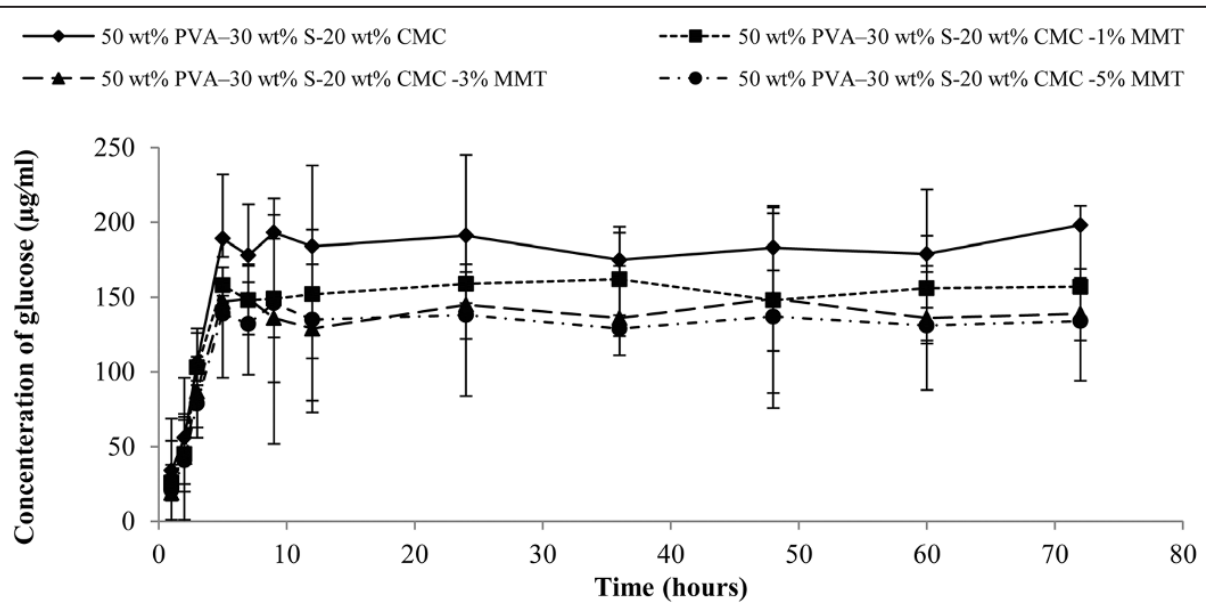

Figure 3 Concentration of glucose produced for nanocomposite films after $\mathbf{7 2} \mathbf{~ h}$ of enzymatic degradation. Values are mean \pm standard deviation $(n=3)$. 
Table 1 Rates of glucose production due to the action of 1-mg cellulase for each substrate

\begin{tabular}{lcc}
\hline Substrate & Rate $(\boldsymbol{\mu} \mathbf{g} / \mathbf{m l} \mathbf{h})$ & $\boldsymbol{R}^{\mathbf{2}}$ \\
\hline PVA/S/CMC & 51.5 & 0.93 \\
PVA/S/CMC/1\% MMT & 45.4 & 0.96 \\
PVA/S/CMC/3\% MMT & 42.8 & 0.96 \\
PVA/S/CMC/5\% MMT & 39.2 & 0.95 \\
\hline
\end{tabular}

\section{Water absorption test}

Pre-dried samples (with freeze dryer FD-10 (Pishtaz Engineering Co., Tehran, Iran)) were weighed for the dry weight and then placed in a bath with distilled water at room temperature. After 1, 2, 5, 8, 24, 30, and $50 \mathrm{~h}$, the samples were removed from distilled water and weighed. The water absorption capability (WAC) was calculated using the following equation:

$$
\mathrm{WAC} \%=\left[\left(\mathrm{W}_{\text {wet }}-\mathrm{W}_{\mathrm{dry}}\right) / \mathrm{W}_{\mathrm{dry}}\right] \times 100,
$$

where $\mathrm{W}_{\text {wet }}$ represents the weight of the wet specimen and $W_{\text {dry }}$ is the weight of the dry specimen.

\section{Detection of reducing sugars}

The reducing sugars in the degradation solutions were quantified by the Nelson-Somogyi method (dinitrosalicylic acid method): $1 \mathrm{ml}$ of reagent DNS was added to $1 \mathrm{ml}$ of the sample to be analyzed [27] using $1 \mathrm{mg} / \mathrm{ml}$ glucose stock solution as a standard. At the same time, the blank was prepared using $1 \mathrm{ml}$ of control sample. The mixture was heated at $90^{\circ} \mathrm{C}$ to $100^{\circ} \mathrm{C}$ for $10 \mathrm{~min}$. After cooling to room temperature, $5 \mathrm{ml}$ of distilled water was added, and the absorbance at $540 \mathrm{~nm}$ was measured. The respective carbohydrate concentration was obtained by comparison with a standard curve. Concentration of glucose produced for nanocomposites after $72 \mathrm{~h}$ and the first $4 \mathrm{~h}$ of enzymatic degradation is due to the action of cellulase at temperature $37^{\circ} \mathrm{C} \pm 1^{\circ} \mathrm{C}$.

\section{FT-IR spectra}

Infrared spectral analysis of the blends, before and after degradation, was carried out by Shimadzu FT-IR RF50 spectrometer (Kyoto, Japan). The samples were prepared using $\mathrm{KBr}$ pellets, and spectra were recorded at a resolution of $4 \mathrm{~cm}^{-1}$.

\section{Scanning electronic microscopy}

Surface morphology of the films, before and after enzymatic degradation, was investigated using a scanning electronic microscope of XL30 type (FEI, Eindhoven, The Netherlands). The films were coated with pure metallic Ag. The laying down of Ag was carried out by evaporation of the metal under a high vacuum to give a thickness of around $100 \AA$.

\section{Results and discussion}

Degradability of polymers is a critical functionality for their application. Currently, no official standard method was established in determining biodegradability of polymers. The enzyme method [30], the microbiological method [31], and the soil burial method [32] have been used by different researchers. Moreover, biodegradability is also recorded by diverse indexes even using the same methods. The present study shows the role of cellulase in PVA/S/CMC/MMT-Na degradation.

\section{Weight loss and water uptake}

The water absorption capacity and the degradability are the most important properties for biodegradable materials. The water absorption capacities of the PVA/ S/CMC blend film were found to have significant

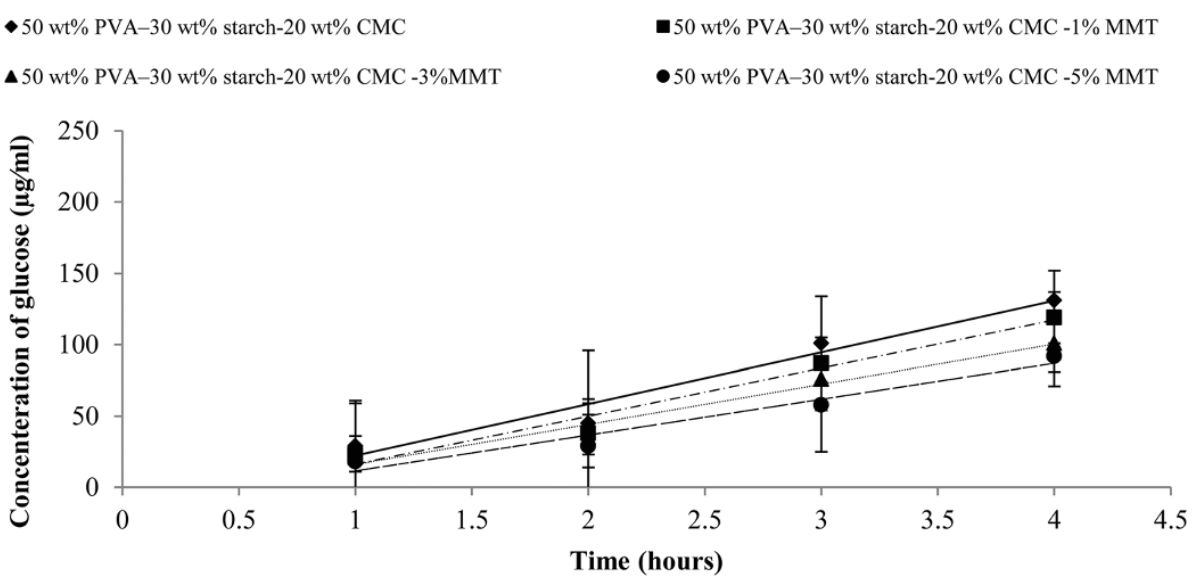

Figure $\mathbf{4}$ Concentration of glucose produced for nanocomposite films in the first $\mathbf{4} \mathbf{h}$ of enzymatic degradation. Values are mean \pm standard deviation $(n=3)$. 


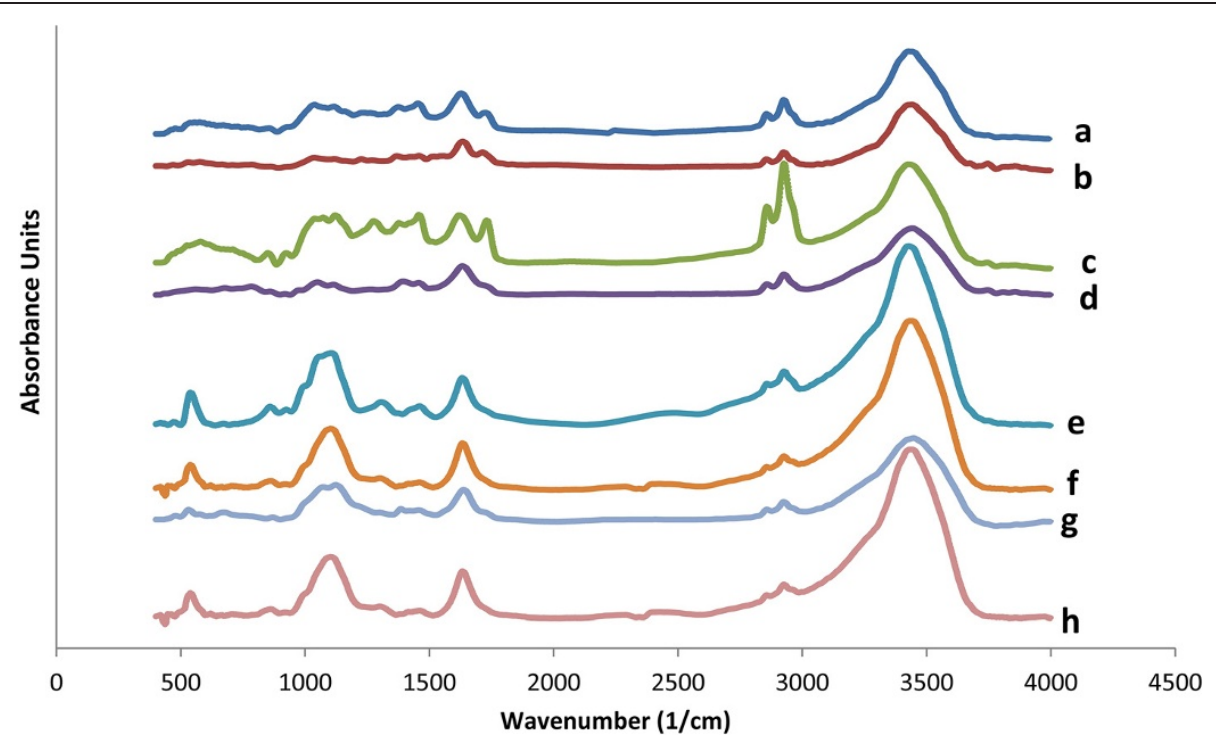

Figure 5 FT-IR spectra of nanocomposite films. (a) PVA/S/CMC undegraded. (b) PVA/S/CMC with 1 wt.\% MMT undegraded. (c) PVA/S/CMC with 3 wt.\% MMT undegraded. (d) PVA/S/CMC with 5 wt.\% MMT undegraded. (e) PVA/S/CMC degraded. (f) PVA/S/CMC with 1 wt.\% MMT degraded. (g) PVA/S/CMC with 3 wt.\% MMT degraded. (h) PVA/S/CMC with 5 wt.\% MMT degraded.

difference. This was consistent with the results of [16] and [24]. The increase of nanoparticle leads to the decrease of both weight loss and water uptake. Figures 1 and 2 clearly show that degradation is much more pronounced when the WAC\% is high. In all concentrations, the addition of MMT decreased the water solubility of films because the layers of MMT act as a barrier against the diffusion of the water to films. A comparison between the variation of the DED\% and WAC\% with respect to sodium montmorillonite clay content clearly shows that degradation is much more pronounced when the water sorption is high. The total solids that remained after 4,320 min were 74.53 wt.\% (PVA/S/CMC), 77.87 wt.\% (PVA/S/CMC/1\% MMT), 80.13 wt.\% (PVA/S/CMC/3\% MMT), and 83.11 wt.\% (PVA/S/CMC/5\% MMT). The hydroxyl groups of MMT can form strong hydrogen bonds with the hydroxyl groups on PVA, starch, and the hydroxyl and carboxyl groups on $\mathrm{CMC}$, thus, improving the interactions between the molecules, improving the cohesiveness of biopolymer matrix, and decreasing the water sensitivity. PVA/S/CMC exhibited both a high water sorption and the most significant weight loss.

\section{Rate and extent of glucose production}

The rate and extent of enzymatic hydrolysis by the action of cellulase were measured using the DNS method glucose assay of four blends of varying MMT. The production of glucose was used as a measure of carboxymethyl cellulose hydrolysis. Figure 3 shows the extent of glucose over a 72-h hydrolysis time for each substrate. Figure 4 illustrates the initial rate of glucose production for each substrate up to a hydrolysis time of $4 \mathrm{~h}$. The rate of glucose production was calculated; refer to Table 1 by assuming a linear relationship between the concentration of glucose and time for the first $4 \mathrm{~h}$ of hydrolysis. The rates of glucose production from each composite substrates were most rapid for the substrate without MMT-Na and decreased with the addition of MMT-Na for PVA/S/CMC blend $(51.5 \mu \mathrm{g} / \mathrm{ml}$ h), PVA/S/CMC/1\% MMT (45.4 $\mu \mathrm{g} / \mathrm{ml} \mathrm{h}), \mathrm{PVA} / \mathrm{S} / \mathrm{CMC} /$ 3\% MMT $(42.8 \mu \mathrm{g} / \mathrm{ml} \mathrm{h})$, and PVA/S/CMC/5\% MMT $(39.2 \mu \mathrm{g} / \mathrm{ml} \mathrm{h})$. The rate of carboxymethyl cellulose hydrolysis was most rapid for the PVA/S/CMC substrate and decreased with the addition of sodium montmorillonite clay. One of the routes of biodegradation is by hydrolysis, and the enzymatic hydrolysis of CMC is accompanied by the release of glucose. Figure 3 shows the release of glucose $(\mu \mathrm{g} / \mathrm{ml})$ during exposure to cellulase. The amount of free glucose increased with time for the blends showed a peak release of glucose at $4 \mathrm{~h}$, followed by a decline. Apparently, the MMT has a stabilizing effect against the enzymatic attack (MMT layers act as a barrier against the diffusion of the enzyme to films), even after increasing the content of insoluble fraction. Each point is the mean of three replicates $(n=3)$; error bars were drawn according to a $95 \%$ confidence interval of each mean.

\section{FT-IR spectra}

Fourier transform infrared (FT-IR) spectra of films before and after enzymatic degradation with cellulase are shown in Figure 5. In this study, attention was focused on the range in the absorption pattern in six main regions: (1) stretching vibration of the $\mathrm{O}-\mathrm{H}$ group between 3,436 and $3,455 \mathrm{~cm}^{-1}$, (2) stretching vibration of the $\mathrm{C}=\mathrm{O}$ at about $1,740 \mathrm{~cm}^{-1}$, (3) stretching vibration of the $\mathrm{C}=\mathrm{C}$ at 


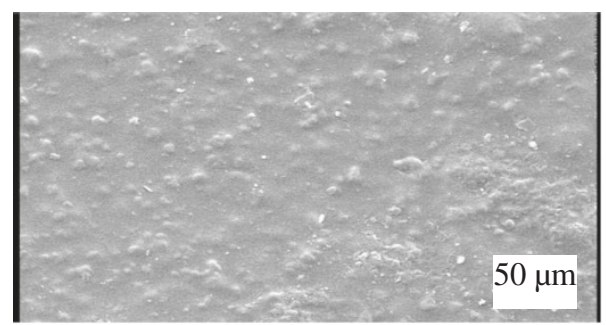

(a)

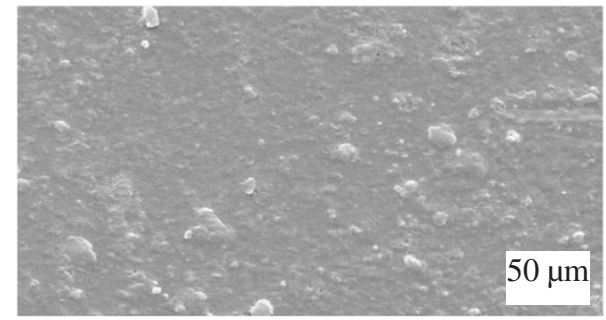

(c)

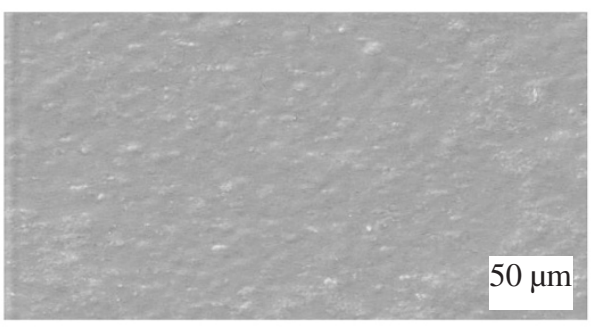

(e)

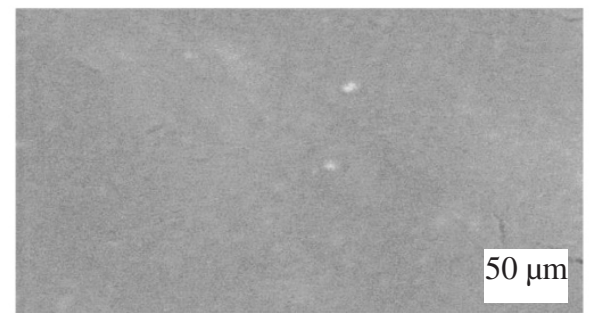

(g)

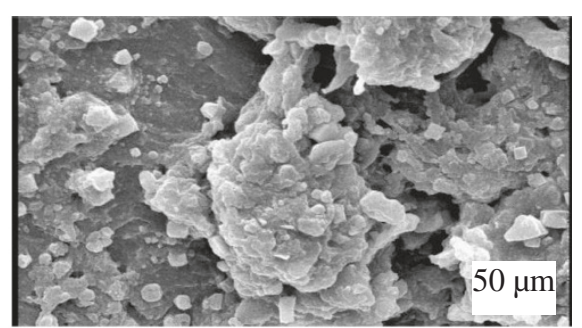

(b)

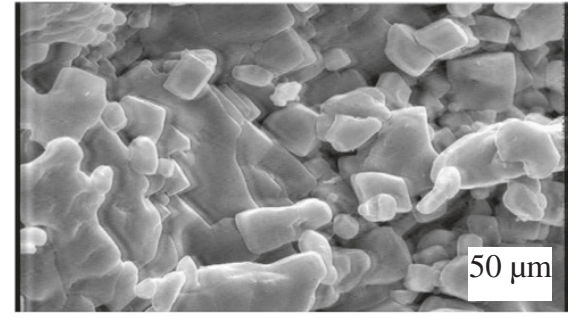

(d)

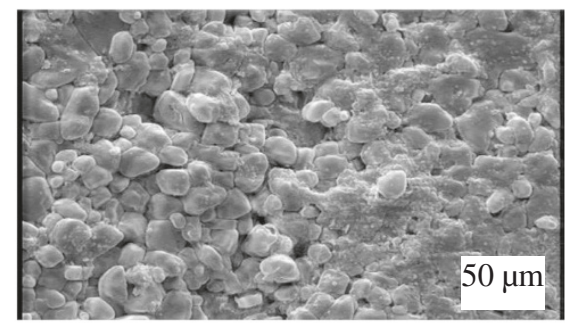

(f)

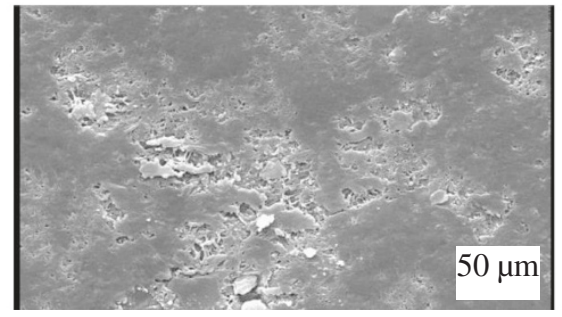

(h)

Figure 6 Scanning electron micrographs. PVA/S/CMC degradable films after $72 \mathrm{~h}$ of enzymatic degradation due to the action of cellulase. (a) PVA/S/CMC undegraded. (b) PVA/S/CMC degraded. (c) PVA/S/CMC with 1 wt.\% MMT undegraded. (d) PVA/S/CMC with 1 wt.\% MMT degraded. (e) PVA/S/CMC with 3 wt.\% MMT undegraded. (f) PVA/S/CMC with 3 wt.\% MMT degraded. (g) PVA/S/CMC with 5 wt.\% MMT undegraded. (h) PVA/S/CMC with 5 wt.\% MMT degraded.

about $1,638 \mathrm{~cm}^{-1}$, (4) stretching vibration of the $\mathrm{C}-\mathrm{O}$ at about $1,237 \mathrm{~cm}^{-1}$, (5) stretching vibration of the $\mathrm{C}-\mathrm{H}$ at about $1,454 \mathrm{~cm}^{-1}$, and (6) stretching vibration of the $\mathrm{COO}^{-}$group between 1,500 and $1,600 \mathrm{~cm}^{-1}$. The broad band in the region of $3,430 \mathrm{~cm}^{-1}$ is due to the hydroxyl stretching vibration, and the band in the region of 2,929 $\mathrm{cm}^{-1}$ is due to $\mathrm{CH}_{2}$ asymmetric and symmetric stretching vibrations. The peak at $1,454 \mathrm{~cm}^{-1}$ was assigned to $\mathrm{CH}_{2}$ bending vibration [33]. The absorbance at 1,115, 1,163, and $1,026 \mathrm{~cm}^{-1}$ is more sensitive to the conformational changes produced during degradation processes, indicating a short range order and helicity changes when crystallinity and molecular orientation are lost. The intensity of the peak at 1,115 and $1,040 \mathrm{~cm}^{-1}$ decreased, indicating the action of cellulase in cleaving the glycosidic linkages of $\mathrm{CMC}$ after incubating with cellulase. The absence of the peak in the 1,740 to $1,720 \mathrm{~cm}^{-1}$ range indicates the absence of aldehyde groups from which it is inferred that all aldehyde groups have been involved in crosslinking [34,35]. The absorption peak from 1,060 to $1,150 \mathrm{~cm}^{-1}$, which can be assigned to the (C-O-C), appears as a shoulder in the spectra of the undegraded films and as a well-defined band in the degraded ones, which also indicates the crosslinking of PVA. 


\section{Scanning electronic microscopy}

Several scanning electronic microscopy images of nanocomposites (in order to compare changes on surface morphology before and after enzymatic degradation with cellulase) are given in Figure 6. Heterogeneity of surfaces decreased as a function of MMT-Na content, as detected on the surface microstructure between the control and more degraded samples (after $72 \mathrm{~h}$ ), being more rough. The MMT has a stabilizing effect against the enzymatic attack (MMT layers act as a barrier against the diffusion of the enzyme to films). One may observe that the films are considerably destroyed, although during degradation a much more stable fibrillar fraction is revealed.

\section{Conclusions}

This present study reports the role of cellulase enzyme in the degradation of nanocomposites. The sodium montmorillonite clay content significantly impacted on the rate of CMC solubilization. Biodegradation behavior of films depends on the content of nanoparticles, and the decrease of the degradation rate observed in the final stage can be explained to the lower degradability of the MMT-PVA-S$\mathrm{CMC}$ domains that remain in the material. After 4 to $72 \mathrm{~h}$, the variation is almost negligible, nearly zero, as no saccharides and other compounds leached to the solution, as demonstrated before. The reduction of the degradation rate is also influenced by the water uptake ability of these polymers. MMT ( $0 \%$ to $5 \% w / w$ film) could decrease the WAC\% and DED\% of PVA/S/CMC/MMT nanocomposite films compared to the PVA/S/CMC films. Considering these results, it seems that the PVA/S/CMC/MMT bionanocomposite films show better physico-chemical properties than PVA/S/CMC films, and they can potentially replace PVA/S/CMC films.

\section{Competing interests}

The authors declare that they have no competing interests.

\section{Authors' contributions}

Both authors read and approved the final manuscript.

\section{Acknowledgements}

We are grateful to University of Tabriz Research Council for the financial support of this research.

Received: 7 May 2013 Accepted: 10 August 2013

Published: 03 Sep 2013

\section{References}

1. Bledzki, AK, Reihmane, S, Gassan, J: Properties and modification methods for vegetable fibers for natural fiber composites. J Appl Polym. Sci. 5, 1329 (1996)

2. Bengtsson, M, Baillif, ML, Oksman, K: Extrusion and mechanical properties of highly filled cellulose fibre-polypropylene composites. Composites Part A: Applied Science and Manufacturing 38, 1922 (2007)

3. Lei, Y, Wu, Q, Yao, F, Xu, Y: Preparation and properties of recycled HDPE/ natural fiber composites. Composites Part A: Applied Science and Manufacturing 38, 1664-1674 (2007)
4. Mulinari, DR, Voorwald, HJC, Cioffi, MOH, Silva, MLCP, Cruz, TG, Saron, C: Sugarcane bagasse cellulose/HDPE composites obtained by extrusion. Compos. Sci. Technol. 69, 214 (2009)

5. Torres, EG, Cubillas, ML: Study of the interfacial properties of natural fiber reinforced polyethylene. Polym. Test. 24, 694 (2005)

6. Iwatake, A, Nogi, M, Yano, H: Cellulose nanofiber-reinforced polylactic acid. Compos. Sci. Technol. 68, 2103 (2008)

7. Chakraborty, A, Sain, M, Kortschot, M: Reinforcing potential of wood pulp derived microfibres in a PVA matrix. Holzforschung 60, 53 (2006)

8. Lu, J, Wang, T, Drzal, LT: Preparation and properties of microfibrillated cellulose polyvinyl alcohol composite materials. Composites Part A: Applied Science and Manufacturing. 39, 738 (2008)

9. Siqueira, G, Bras, J, Dufresne, A: Cellulose whiskers versus microfibrils:Influence of the nature of the nanoparticle and its surface functionalization on the thermal and mechanical properties of nanocomposites. Biomacromolecules 10, 425 (2009)

10. Ramaraj, B: Crosslinked poly(vinyl alcohol) and starch composite films. II. Physicomechanical, thermal properties and swelling studies. J. Appl. Polym. Sci. 103, 909 (2007)

11. Chen, N, Li, L, Wang, Q: New technology for thermal processing of poly (vinyl alcohol). Plastics, Rubber and Composites: Macromolecular Engineering 36, 283 (2007)

12. Chen, $Y$, Cao, $X$, Chang, PR, Huneault, MA: Comparative study on the films of poly(vinyl alcohol)/pea starch nanocrystals and poly(vinyl alcohol)/ native pea starch. Carbohydr. Polym. 73, 8 (2008)

13. Zimmermann, T, Phler, E, Geiger, T: Cellulose fibrils for polymer reinforcement. Adv. Eng. Mater 6, 754 (2004)

14. Dong, J, Dicharry, R, Waxman, E, Parnas, RS, Asandei, AD: Imaging and thermal studies of wheat gluten/poly(vinyl alcohol) and wheat gluten/ thiolated poly(vinyl alcohol) blends. Biomacromolecules 9, 568 (2008)

15. Ma, X, Chang, PR, Yu, J: Properties of biodegradable thermoplastic pea starch/carboxymethyl cellulose and pea starch/microcrystalline cellulose composites. Carbohydr. Polym. 72, 369 (2008)

16. Taghizedeh, MT, Abbasi, Z, Nasrolahzadeh, Z: Study of enzymatic degradation and water absorption of nanocomposites starch/polyvinyl alcohol and sodium montmorillonite clay. J Taiwan Inst. Chem. Eng. 43, 120 (2012)

17. Mathew, AP, Dufresne, A: Plasticized wazy maize starch: Effect of polyols and relative humidity on material properties. Biomacromolecules 3, 1101 (2002)

18. Chaleat, CM, Halley, PJ, Truss, RW: Properties of a plasticised starch blend Part 1: Influence of moisture content on fracture properties. Carbohydr. Polym. 71(4), 535 (2008)

19. Ray, SS, Okamoto, M: Polymer/layered silicate nanocomposites: a review from preparation to processing. Prog. Polym. Sci 28(11), 1539 (2003)

20. Tjong, SC: Structural and mechanical properties of polymer nanocomposites. Mater. Sci. Eng. 53, 73 (2006)

21. Lx Griffin, GJ: Biodegradable fillers in thermoplastics. ACS Advances in Chemistry 134, 159-170 (1974)

22. Bastioli, C, Bellotti, V, Giudice, LD, Gilli, G: Microstructure and biodegradability of Mater-Bi products. In: Vert, M., Feijen, J., Albertsson, A., Scott, G., Chiellini, E. (eds.) Biodegradable Polymers and Plastics, pp. 101110. The Royal Society of Chemistry, Cambridge (1992)

23. Bajpai, AK., Shrivastava, J: In vitro enzymatic degradation kinetics of polymeric blends of crosslinked starch and carboxymethyl cellulose. Polym. Int. 54(11), 1524 (2005)

24. Abbasi, Z: Water resistance, weight loss and enzymatic degradation of blends starch/polyvinyl alcohol containing $\mathrm{SiO} 2$ nanoparticle. J. Taiwan Inst. Chem. Eng. 43, 264 (2012)

25. Abbasi, Z, Alikarami, M, Taghizedeh, MT, Sabouri, N, Raoufi, F: Study of Enzymatic Degradation and Water Absorption of Thermoplastic Cellulose-Clay Nanocomposites. Journal of Chemical Science and Technology. 1(3), 70 (2012)

26. He, D, Bao, L, Long, Y, Wei, W, Yao, S: A new study of the enzymatic hydrolysis of carboxymethyl cellulose with a bulk acoustic wave sensor. Talanta 50, 1267 (2000)

27. Miller, GL.: Use of dinitrosalicylic acid reagent for determination of reducing sugar. Anal. Chem. 3, 426 (1959)

28. Taghizadeh, MT, Sabouri, N, Ghanbarzadeh, B: Physical and mechanical properties of polyvinyl alcohol/starch/ carboxy methyl cellulose/ montmorillonite nanocomposite films. Nano Science and Nano Technology (an Indian journal) 6(2), 54 (2012)

29. Taghizadeh, MT, Sabouri, N, Ghanbarzadeh, B: Mechanical, thermal and morphological properties of polyvinyl alcohol/starch/carboxy methyl cellulose biodegradable blends. Macromolecules (an Indian journal) 8(2), 29 (2012) 
30. Benedict, CV, Cook, WJ, Jarrett, P, Cameron, JA, Huang, SJ, Bell, JP: Fungal degradation of polycaprolactones. J Appl. Polym. Sci. 28, 327 (1983)

31. Huskic, M, Brnardic, I, Zigon, M, Ivankovic, M: Modification of montmorillonite by quaternary polyesters. J Non-Cryst Solids. 354,3326 (2008)

32. $\mathrm{Xu}, \mathrm{YX}$, Hanna, MA: Preparation and properties of biodegradable foams from starch acetate and poly (tetramethylene adipate-co-terephthalate). Carbohydr. Polym. 59, 521 (2005)

33. Kim, DH, Na, SK, Park, JS: Preparation and characterization of modified starchbased plastic film reinforced with short pulp fiber. I. Structural properties. J. Appl. Polym. Sci. 88, 2100 (2003)

34. Spiridona, I, Popescua, MC, Bodarlaua, R, Vasile, C: Enzymatic degradation of some nanocomposites of poly(vinyl alcohol) with starch. Polym. Degrad. Stab. 93, 1884 (2008)

35. Pal, K, Banthia, AK, Majumdar, DK: Preparation of transparent starch based hydrogel membrane with potential application as wound dressing. Trends Biomater Artif Organs 20(1), 59 (2006)

10.1186/2228-5326-3-51

Cite this article as: Taghizadeh and Sabouri: Biodegradation behaviors and water adsorption of poly(vinyl alcohol)/starch/carboxymethyl cellulose/clay nanocomposites. International Nano Letters 2013, 3:51

\section{Submit your manuscript to a SpringerOpen ${ }^{\circ}$ journal and benefit from:}

- Convenient online submission

- Rigorous peer review

- Immediate publication on acceptance

- Open access: articles freely available online

- High visibility within the field

- Retaining the copyright to your article 